\title{
A different option in vascular bone grafts in the hand and wrist region: Use of a dorsoulnar artery-based osteo-fascio-cutaneous flap: A case series
}

\author{
Osman Orman, $\mathrm{MD}^{1}{ }^{1}$, Fikret Eren, $\mathrm{MD}^{2}{ }^{-1}$, Ahmet Duran Kara, $\mathrm{MD}^{3}\left(\mathbb{D}\right.$, Ceyhun Cesur, $\mathrm{MD}^{4}(\mathbb{D}$, \\ Cengiz Yıldırım, $\mathrm{MD}^{5}$ (D) Bilge Kağan Aysal, $\mathrm{MD}^{6}{ }^{\infty}$
}

1Department of Hand Surgery, Istanbul Metin Sabancı Baltalimanı Bone Diseases Training and Research Hospital, Istanbul, Turkey ${ }^{2}$ Plastic and Reconstructive Surgery, Private Practice, Antalya, Turkey

${ }^{3}$ Department of Orthopedics and Traumatology, Rumeli University, Reyap Hospital, İstanbul, Turkey

${ }^{4}$ Department of Plastic and Reconstructive Surgery, Bodrum State Hospital of the Ministry of Health, Muğla, Turkey

${ }^{5}$ Department of Orthopedics and Traumatology, Sultan Abdülhamid Han Training and Research Hospital, Istanbul, Turkey

${ }^{6}$ Department of Plastic and Reconstructive Surgery, Muğla Sıtkı Koçman University, Muğla, Turkey

Vascularized bone grafts (VBG) are important options for the reconstruction of bone loss in the hands and wrists. Unlike non-vascularized bone grafts (NVBG), the blood circulation of the bone tissue taken from the donor site is preserved in VBGs. Thus, osteoclasts and osteoblasts survive and allow for primary bone union without any creeping substitution, minimizing any resorption of the graft and risk of mechanical failure. ${ }^{[1-3]}$ However, VBGs are technically demanding and cause greater donor site morbidities.

Received: October 09, 2020

Accepted: February 01, 2021

Published online: June 11, 2021

Correspondence: Osman Orman, MD. İstanbul Metin Sabancı Baltalimanı Kemik Hastalıkları Eğitim ve Araştırma Hastanesi, El Cerrahisi Kliniği, 3447 Sarıyer, İstanbul, Türkiye.

E-mail: osmanorman@gmail.com

Doi: $10.52312 /$ jdrs.2021.79298

Citation: Orman O, Eren F, Kara AD, Cesur C, Yıldırım C, Aysal BK. A different option in vascular bone grafts in the hand and wrist region: Use of a dorsoulnar artery-based osteo-fascio-cutaneous flap: A case series. Jt Dis Relat Surg 2021;32(2):504-513.

(02021 All right reserved by the Turkish Joint Diseases Foundation

This is an open access article under the terms of the Creative Commons Attribution-NonCommercial License, which permits use, distribution and reproduction in any medium, provided the original work is properly cited and is not used for commercial purposes (http://creativecommons.org/licenses/by-nc/4.0/)

\section{ABSTRACT}

Objectives: This study aims to describe our surgery technique and discuss patients treated through the dorsoulnar artery (DUA)-based technique of osseous and osteo-fascio-cutaneous vascularized ulnar bone grafting.

Patients and methods: Between January 2011 and January 2015, six male patients (median age: 22.5 years; range, 20 to 24 years) who underwent surgery during which the technique of DUA ulnar bone graft was utilized. One patient with scaphoid nonunion, three patients with Kienböck's disease, and two patients with a traumatic metacarpal defect were retrospectively evaluated. The joint range of motion (ROM), grip strength, Disabilities of the arm, shoulder and Hand (DASH) questionnaire score and Visual Analog Scale (VAS) score, and radiographies before and after surgery were examined. Scintigraphy was performed at 12 weeks postoperatively to monitor the viability of the bone graft.

Results: All patients showed improvements in the ROM, grip strength, VAS, and DASH scores. According to the radiographic examination, bone union was achieved in all patients and the scintigraphy revealed that vascularization was detected in the bone tissue.

Conclusion: The advantages of DUA-based vascularized bone graft are good bone quality and quantity and versatility due to its long pedicle. The osteo-fasio-cutaneous DUA flap seems to be effective in the treatment of traumatic metacarpal bone defects accompanied by skin loss. The DUA-based vascularized ulnar bone may be a source for scaphoid and lunate biological bone reconstruction.

Keywords: Bone reconstruction, Kienböck's disease, scaphoid nonunion, vascularized bone graft.

In the literature, it has been reported that some of the bone sites from which pedicled VBGs are obtained include the distal radius, ulna, carpal bones, and metacarpal bones. ${ }^{[4-10]}$ In addition, the 
literature on grafting also includes studies that refer to free VBGs from the metatarsals and medial femoral condyle. Grafts obtained from the distal radius are usually the preferred option for scaphoid and lunate bone reconstructions, while grafts obtained from other metacarpals are preferred for metacarpal bone reconstructions. However, distal radius as a donor site for scaphoid and lunate biological bone reconstruction has some constraints to be considered, as in previous surgeries distal radius vasculature might be disrupted. ${ }^{[1]}$ Also, the pedicle length may limit its reach to the recipient site; as a result, radial styloidectomy may become inevitable. ${ }^{[5]}$ Another constraint to consider about the hand and wrist as a donor site is the possible need for osteo-fasciocutaneous flaps for skin losses accompanying the bone defect.

Becker and Gilbert ${ }^{[12]}$ first described in 1988 a 1 to $1.3-\mathrm{mm}$ diameter artery that rises from ulnar artery deep to flexor carpi ulnaris and supplies the skin and the fascia in the distal two thirds of the ulnar side of the forearm, and a flap based on this vessel can repair defects in the dorsal and palmar aspects of the hand and wrist, the thenar and the hypothenar eminence. Anatomical studies have demonstrated that the ulnar artery gives rise to the dorsal ulnar branch which is approximately $4.1 \mathrm{~cm}$ $(3.2$ to $5.5 \mathrm{~cm})$ at a mean distance proximal to the pisiform bone. Then, it gives off a muscular branch, an osseous one, and a cutaneous one. The cutaneous branch is divided into two branches: an ascending branch and a descending one. The descending branch is anastomosed with a deep arch in the volar after passing through the posterior of the pisiform bone (Figure 1). Distally based flaps are elevated with respect to these anastomoses. With the inclusion of the descending branch, the pedicle length can reach up to $6 \mathrm{~cm}$, and a pedicle diameter of $1.06 \mathrm{~mm}$ (0.65 to $1.64 \mathrm{~mm})$ can be observed ${ }^{[13]}$ Subsequently, the pedicle can be extended by modification of the distal base. ${ }^{[14,15]}$ In 2004, Choupina et al., ${ }^{[16]}$ for the first time, illustrated how this applied as an osteocutaneous flap in a patient with a metacarpal bone and soft tissue defect. ${ }^{[16]}$

In the present study, we summarize the surgical technique of the dorsoulnar artery (DUA) osteo-fascio-cutaneous flap for VBGs and its clinical results in the treatment of patients with Kienböck's disease, scaphoid nonunion, and traumatic metacarpal bone defects. The study for the first time provides a detailed explication of the utilization of this VBG in the treatment of Kienböck's disease and scaphoid nonunion. The aim of the study was to demonstrate our surgical technique of DUA osseous and osteo-fascio-cutaneous flap and the results of six patients diagnosed with scaphoid nonunion, Kienböck's disease, and traumatic metacarpal defect.

\section{PATIENTS AND METHODS}

This retrospective study was conducted at Sultan Abdülhamid Han Training and Research Hospital between January 2011 and January 2015. The data obtained from the patients aged between 18 and 59 years who underwent DUA-based flap surgery were retrospectively analyzed. Of the patients, those receiving the treatment of DUA-based flaps with vascularized bone component were included. Patients with a follow-up duration less than six months were excluded. One case with scaphoid nonunion (undergoing scaphoid nonunion surgery through non-vascularized bone grafting 13 months before; Slade and Geissler Type 5), three cases with Kienböck's disease (one with Lichtman Type 2, two with Lichtman Type 3a), and two cases with traumatic metacarpal defects were selected for the study (Table I). ${ }^{[17,18]}$ A written informed consent was
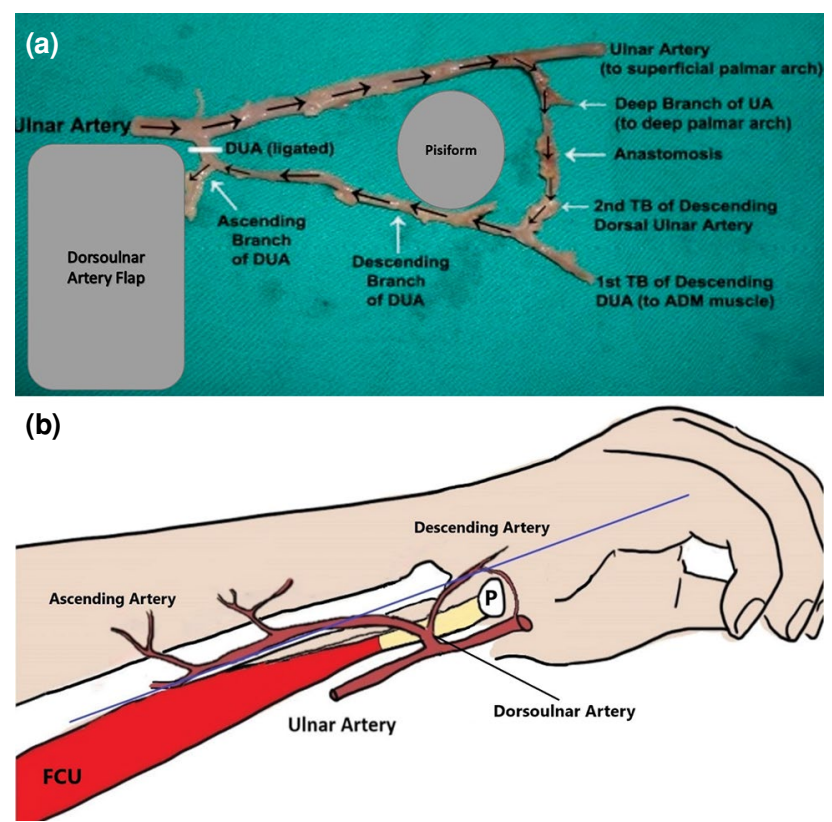

FIGURE 1. (a) Cadaver dissection: Dorsoulnar artery (DUA) showing the ascending and descending branches with anastomosis distal to pisiform bone. (b) Schematic representation of DUA and relations with pisiforme, flexor carpi ulnaris and ulnar artery; the line was drawn as an axis extending from 0.5 to $1 \mathrm{~cm}$ volar to the styloid process of the ulna to the fourth digital space represents the course of DUA. UA: UInar artery; DUA: Dorsoulnar artery; P: Pisiforme; FCU: Flexor carpi ulnaris; ADM: Abductor digiti minimi; TB: Terminal branch (Figure 1a, with the courtesy of Hüseyin Karagöz). 


\begin{tabular}{|c|c|c|c|c|c|c|}
\hline \multicolumn{7}{|c|}{$\begin{array}{c}\text { TABLE I } \\
\text { Etiology, age, sex, and time elapsed until surgery of the patients }\end{array}$} \\
\hline Patient & Etiology & Age/Sex & Side & Time till surgery & Classification & Radiologic angles \\
\hline 1 & Scaphoid nonunion & 24/Male & Left & 28 months & $\begin{array}{l}\text { Slade and } \\
\text { Geissler type V }\end{array}$ & $\begin{array}{l}\text { Preop.: SL: } 65^{\circ}, \mathrm{RL}: 6^{\circ} \text {, ISA: } 15^{\circ} \\
\text { Postop.: SL: } 48^{\circ}, \mathrm{RL}: 8^{\circ}, \mathrm{ISA}: 13^{\circ}\end{array}$ \\
\hline 2 & Kienböck's disease & 22/Male & Right & 4 months & Lichtman type 2 & $\begin{array}{l}\text { Preop.: SL: } 36^{\circ}, \mathrm{RL}: 9^{\circ} \text {, ISA: } 15^{\circ}, \mathrm{CHR}: 0.5 \\
\text { Postop.: SL: } 32^{\circ}, \mathrm{RL}: 6^{\circ} \text {, ISA: } 15^{\circ} \text {, CHR: } 0.47\end{array}$ \\
\hline 3 & Kienböck's disease & 22/Male & Left & 9 months & Lichtman type $3 а$ & $\begin{array}{l}\text { Preop.: SL: } 39^{\circ}, \mathrm{RL}: 9^{\circ}, \mathrm{ISA}: 12^{\circ}, \mathrm{CHR}: 0.5 \\
\text { Postop.: SL: } 34^{\circ}, \mathrm{RL}: 12^{\circ}, \mathrm{ISA}: 14^{\circ}, \mathrm{CHR}: 0.48\end{array}$ \\
\hline 4 & Kienböck's disease & 23/Male & Left & 6 months & Lichtman type $3 а$ & $\begin{array}{l}\text { Preop.: SL: } 48^{\circ} \text {, RL: } 11^{\circ} \text {, ISA: } 10^{\circ} \text {, CHR: } 0.48 \\
\text { Postop.: SL: } 46^{\circ}, \mathrm{RL}: 12^{\circ} \text {, ISA: } 10^{\circ} \text {, CHR: } 0.5\end{array}$ \\
\hline 5 & $\begin{array}{l}\text { Traumatic metacarpal } \\
\text { bone defect }\end{array}$ & 20/Male & Left & 3 days & $\begin{array}{l}\text { Gustilo-Anderson } \\
\text { type } 3 C\end{array}$ & \\
\hline 6 & $\begin{array}{l}\text { Traumatic metacarpal } \\
\text { bone defect }\end{array}$ & 24/Male & Right & 5 days & $\begin{array}{l}\text { Gustilo-Anderson } \\
\text { type } 3 C\end{array}$ & \\
\hline
\end{tabular}

obtained from each patient. The study protocol was approved by the Istanbul Prof. Dr. Cemil Taşcioğlu State Hastanesi Ethics Board (No: 48670771-514.10). The study was conducted in accordance with the principles of the Declaration of Helsinki.

All the patients were male. The median age of the patients was 22.5 (range, 20 to 24 ) years. The joint range of motion (ROM) was measured by goniometry, and grip strength was measured by Jamar ${ }^{\circledR}$ dynamometer (Sammons. Preston, Rolyon, Bolingbrook, IL, USA) before and after surgery. In addition, the Disabilities of the Arm, Shoulder and Hand (DASH) and Visual Analog Scale (VAS) scores were calculated. The patients underwent pre- and postoperative anteroposterior and lateral radiographies on a monthly basis until the sixth month to display scapholunate angle, radiolunate angle, and interscaphoid angle for scaphoid nonunion. The carpal height ratio for Kienböck's disease was evaluated pre- and postoperatively (Table II). A postoperative $12^{\text {th }}$ week scintigraphy was performed to monitor the viability of the bone graft. ${ }^{[19]}$ The patients' lack of any complaints about pain or tenderness and the radiographic proof of the existence of bridging callus at fracture sites were regarded as indicators of union.

\section{TABLE II}

The VAS and DASH scores, grip strength, time to return to work, and ROM of the involved joint of patients

\begin{tabular}{|c|c|c|c|c|c|c|c|}
\hline Patient & Etiology & VAS score & $\begin{array}{l}\text { Wrist }{ }^{*} / M P \text { active } \\
\text { flexion/extension }\end{array}$ & $\begin{array}{l}\text { Wrist radial/ulnar } \\
\text { deviation }\end{array}$ & $\begin{array}{l}\text { Grip strength } \\
(\mathrm{kg})\end{array}$ & DASH score & Time to return work \\
\hline \multirow{2}{*}{1} & \multirow{2}{*}{$\begin{array}{l}\text { Scaphoid } \\
\text { non-union }\end{array}$} & Preop.: 7 & Preop.: $15^{\circ} / 15^{\circ}$ & Preop.: $10^{\circ} / 15^{\circ}$ & Preop.: 30 & Preop.: 54.3 & \multirow{2}{*}{6 months } \\
\hline & & Postop.: 1 & Postop.: $30 \% 30^{\circ}$ & Postop.: $10 \% 15^{\circ}$ & Postop.: 35 & Postop.: 32.5 & \\
\hline \multirow{2}{*}{2} & \multirow{2}{*}{$\begin{array}{l}\text { Kienböck's } \\
\text { disease }\end{array}$} & Preop.: 7 & Preop.: $30^{\circ} / 15^{\circ}$ & Preop.: $15^{\circ} / 15^{\circ}$ & Preop.: 35 & Preop.: 50 & \multirow{2}{*}{4 months } \\
\hline & & Postop.: 3 & Postop.: $30^{\circ} / 45^{\circ}$ & Postop.: $10^{\circ} / 20^{\circ}$ & Postop.: 43 & Postop.: 26.7 & \\
\hline \multirow{2}{*}{3} & \multirow{2}{*}{$\begin{array}{l}\text { Kienböck's } \\
\text { disease }\end{array}$} & Preop.: 8 & Preop.: $45^{\circ} / 45^{\circ}$ & Preop.: $15^{\circ} / 10^{\circ}$ & Preop.: 25 & Preop.: 53.3 & \multirow{2}{*}{5 months } \\
\hline & & Postop.: 1 & Postop.: $45^{\circ} / 45^{\circ}$ & Postop.: $10 \% 15^{\circ}$ & Postop.: 31 & Postop.: 28.3 & \\
\hline \multirow{2}{*}{4} & \multirow{2}{*}{$\begin{array}{l}\text { Kienböck's } \\
\text { disease }\end{array}$} & Preop.: 6 & Preop.: $40^{\circ} / 15^{\circ}$ & Preop.: $10^{\circ} / 10^{\circ}$ & Preop.: 45 & Preop.: 54.3 & \multirow{2}{*}{4 months } \\
\hline & & Postop.: 2 & Postop.: $45^{\circ} / 30^{\circ}$ & Postop.: $10 \% 10^{\circ}$ & Postop.: 48 & Postop.: 22.5 & \\
\hline \multirow{2}{*}{5} & \multirow{2}{*}{$\begin{array}{l}\text { Tr. MC } \\
\text { bone defect }\end{array}$} & Preop.: 9 & Preop.: $45^{\circ} / 40^{\circ}$ & & Preop.: 0 & Preop.: 73.3 & \multirow{2}{*}{9 months } \\
\hline & & Postop.: 2 & Postop.: $70 \%-30^{\circ}$ & & Postop.: 25 & Postop.: 22.5 & \\
\hline \multirow{2}{*}{6} & \multirow{2}{*}{$\begin{array}{l}\text { Tr. MC } \\
\text { bone defect }\end{array}$} & Preop.: 9 & Preop.: $55 \%-45^{\circ}$ & & Preop.: 0 & Preop.: 67.2 & \multirow{2}{*}{8 months } \\
\hline & & Postop.: 3 & Postop.: $70 \%-10^{\circ}$ & & Postop:: 32 & Postop.: 15.8 & \\
\hline
\end{tabular}

VAS: Visual Analog Scale; DASH: Disabilities of the Arm, Shoulder and Hand; ROM: Range of motion; MP: Metacarpophalangeal joint; Preop.: Preoperative; Postop.: Postoperative; Tr.: Traumatic; MC: Metacarpal. 


\section{Surgical technique}

A tourniquet was applied to all patients after the upper extremity was elevated for $3 \mathrm{~min}$. The tourniquet was, then, inflated in accordance with the patient's blood pressure. For the patients with metacarpal bone and skin defects in the dorsum of the hand, the amount of bone and soft tissue required for surgery was determined after the process of debridement. As for the patient with scaphoid nonunion, an incision was made between the flexor carpi radialis tendon and radial artery. Subsequently, the volar joint capsule was opened longitudinally to gain access to the nonunion area. For the patients with avascular necrosis, the lunate was reached through the dorsal. During the process, after we passed through the fourth extensor compartment, the sensory branch of the posterior interosseous nerve was located and cauterized. The lunate was reached by means of the elevation of the dorsal wrist capsule radially and the tourniquet was, then, deflated.

The ascending branch of the DUA was located with the hand Doppler ultrasound (Huntleigh Sonicaid SD2) during surgery. The reference points for the perforator artery were marked to allow for a length of 2 to $4-\mathrm{cm}$ proximal to the pisiform. A reference line which resembles DUA was drawn across the fourth web to $1 \mathrm{~cm}$ from volar to ulna styloid. The flap was designed to remain within the lower one-third of the front arm between the flexor carpi ulnaris (FCU) tendon in the volar and the fourth and fifth extensor digitorum communis in the dorsal. The skin flap in patients with skin and bone defects was designed to be of the appropriate size ( $\max 10$ to $20 \mathrm{~cm}$ long and 5 to $10 \mathrm{~cm}$ wide); on the other hand, in those cases where only the bone component was required, the monitor flap was marked as $2 \times 1 \mathrm{~cm}$ in size (pedicle length and diameter data given in Table III). Any skin defect at the flap donor site less than $5 \mathrm{~cm}$ wide was closed primarily, whereas any defect in larger sizes required skin grafting.
The tourniquet was inflated again as described before. The incision was initiated in the area around the flap planned, and the muscle fascia was also incised to reach the periosteum. Depending on the amount of bone needed, an area on the ulna was determined (approximately $4 \times 1 \mathrm{~cm}$ for the metacarpal; $10 \times 5 \mathrm{~mm}$ for the scaphoid and lunate) and the periosteum was cut with a scalpel. Within this predefined area, several holes were drilled with a 1-mm Kirschner wire (K-wire), which were, then, joined together using an osteotome. The pedicle was dissected from proximal to distal with approximately 3 -cm wide tissue, including subcutaneous tissue and the aponeurosis of FCU to protect artery and the accompanying veins. It was ensured that the dissection of the pedicle did not extend distal to pisiform. After the flap was elevated, the tourniquet was released, and the bleeding was checked. The most critical task during the flap removal and transportation was to prevent the peeling of the periosteum off the bone. To achieve this, the periosteum was temporarily sutured to the bone with the help of bone tunnels. The tunnels were prepared to be drilled with a $1 \mathrm{~mm}$ K-wire at 2 to $4-\mathrm{mm}$ intervals. The flap was rotated from the point that is $1.5 \mathrm{~cm}$ dorsal to pisiform proximal pole and was carried to the recipient site either through a subcutaneous tunnel or for large skin flaps through an incision between the donor and recipient sites. The bleeding was checked once again, after the flap was transferred to the recipient site.

In the patients with metacarpal defects, the bone graft was tapered at both ends, placed in a cone-shaped cup into metacarpal remnants and subsequently can be fixed with transverse K-wires, cerclage wires, and/or screws. As for the patient with a defect in the scaphoid bone, bone grafts were placed as a block inside rectangular bone cavities which were prepared in the proximal and distal scaphoid and, then, fixed with a headless compressive screw. In the patients with avascular necrosis in the lunate bone, the inside of the lunate was carved with a burr.

\begin{tabular}{|clcc|}
\multicolumn{5}{c}{ TABLE III } \\
Patient & Etiology & Pedicle length & Pedicle diameter $(\mathrm{mm})$ \\
\hline 1 & Scaphoid non-union & $5.5 \mathrm{~cm}$ & 1 \\
2 & Kienböck's disease & $5.0 \mathrm{~cm}$ & 1.2 \\
3 & Kienböck's disease & $5.2 \mathrm{~cm}$ & 1 \\
4 & Kienböck's disease & $5.0 \mathrm{~cm}$ & 1 \\
5 & Traumatic metacarpal bone defect & $6.5 \mathrm{~cm}$ & 1.1 \\
6 & Traumatic metacarpal bone defect & $6.0 \mathrm{~mm}$ & 1.2 \\
\hline
\end{tabular}


Next, the bone graft was placed inside the lunate and sutured to the periosteal soft tissue with absorbable sutures. The soft tissue components of the flap were, then, sutured to the surrounding tissues. As a final step, the injured area was stabilized with a below-elbow splint (Figure 2).

\section{RESULTS}

The patient with scaphoid nonunion with humpback deformity (with scapholunate angle being preoperatively $65^{\circ}$, and postoperatively $48^{\circ}$ ) displayed an increase of $15^{\circ}$ flexion, $15^{\circ}$ extension in wrist motion and a 5-kg increase in the grip strength after surgery (compared with the other side, $64 \%$ deficiency of total wrist ROM and $26 \%$ deficiency of grip strength persisted). His VAS score was reduced by six points, while the DASH score was reduced by 19.8 points. The patient returned to work six months later (Figure 3).
The median wrist ROM of three patients with Kienböck's disease (one patient with ulna $1-\mathrm{mm}$ negative) increased by $16.7^{\circ}$ ( $15^{\circ}$ flexion, $1.7^{\circ}$ extension) after surgery. The median grip strength of these patients rose by $5.6 \mathrm{~kg}$ (compared to the other side, the median deficiency $53 \%$ of total wrist ROM and the median deficiency $12 \%$ of grip strength persisted). The median VAS score fell by five points and the DASH score decreased by a median of 27.5 points. The patients returned to work after a median duration of 4.3 months (Figure 4).

For two patients with traumatic metacarpal defect, a median increase of $42.5^{\circ}\left(20^{\circ}\right.$ flexion, $22.5^{\circ}$ extension) was observed in metacarpophalangeal (MP) joint $\mathrm{ROM}$ at the injured metacarpal bone, and the grip strength increased by a median of $28.5 \mathrm{~kg}$ (compared to the other sides, $55 \%$ deficiency of total MP ROM and $36.6 \%$ deficiency in the grip strength persisted). The VAS score fell by a median of 6.5 points, and a
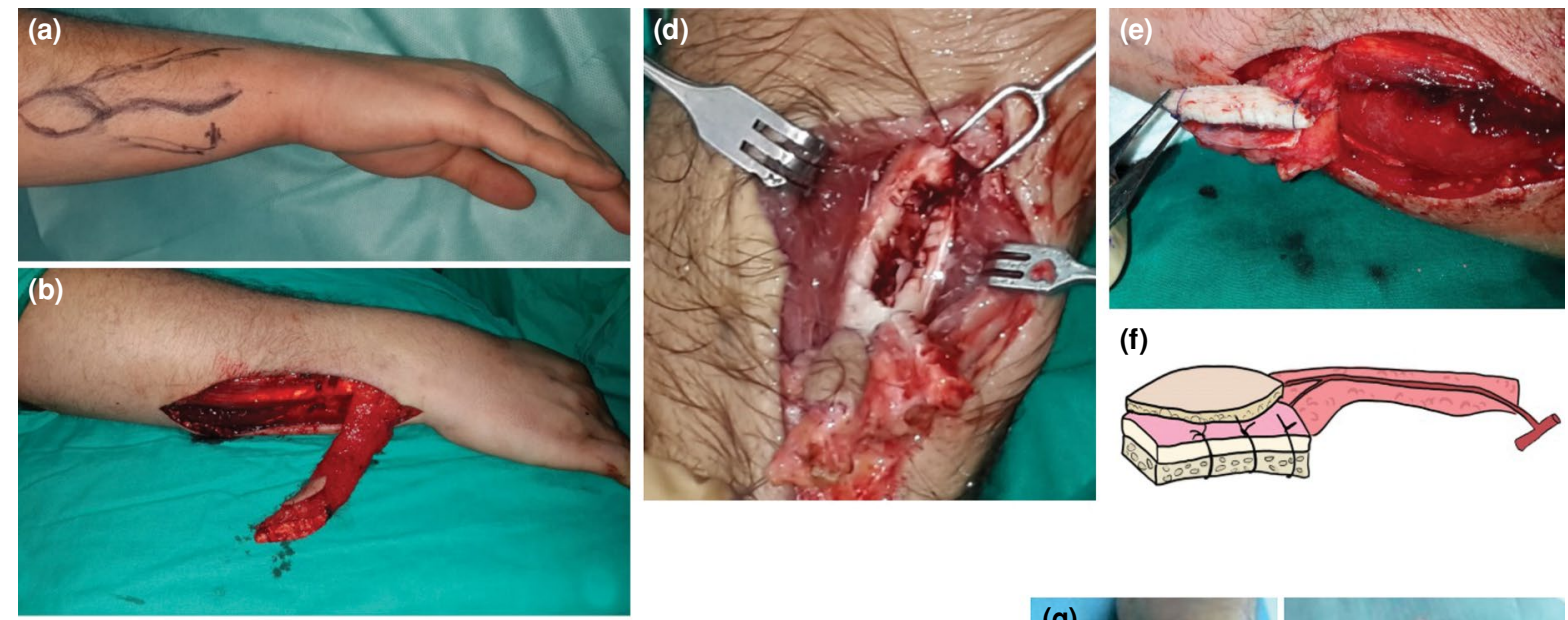

(f)
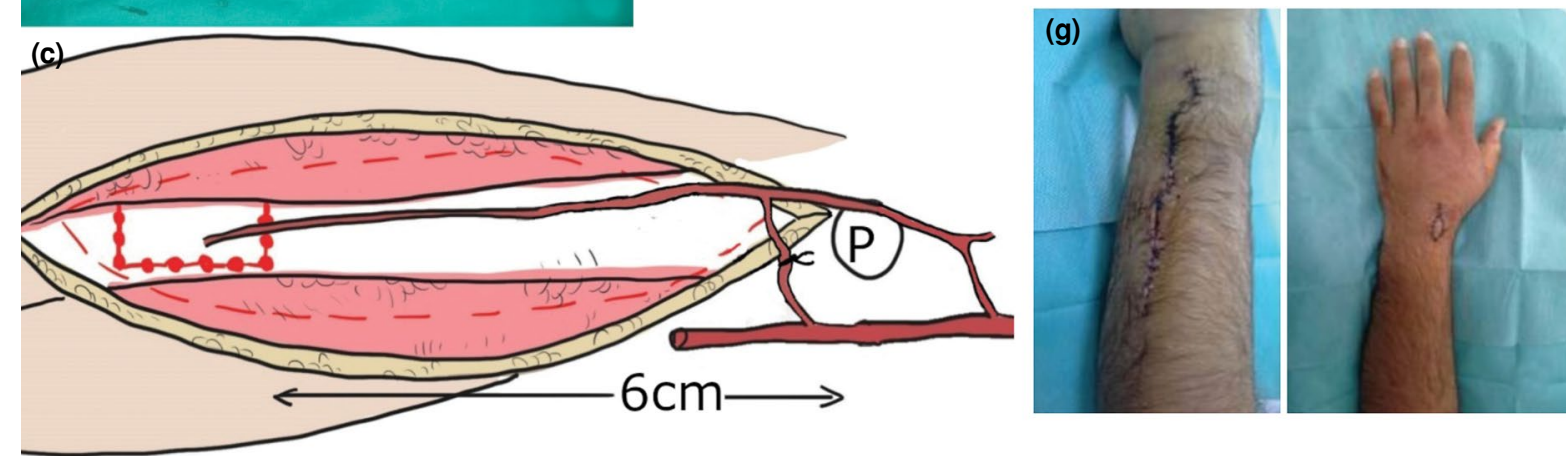

FIGURE 2. Surgical technique: (a) Marking of the flap to a Kienböck's disease patient's left arm. (b) Elevated ulnar bone graft with its pedicle. (c) Schematic representation of the flap, dorsoulnar artery can be dissected and ligated just proximal to the site where it ramifies into the descending and ascending branches so that the pedicle length can reach to $6 \mathrm{~cm}$. (d) Elevating bone graft via drill holes. (e) Elevated ulnar bone graft with its pedicle, periosteum is sutured to bone. (f) Schematic representation of the flap; periosteum is sutured to bone, pedicle is raised with the surrounding subcutaneous tissue. (g) Closure of the donor and recipient site. 

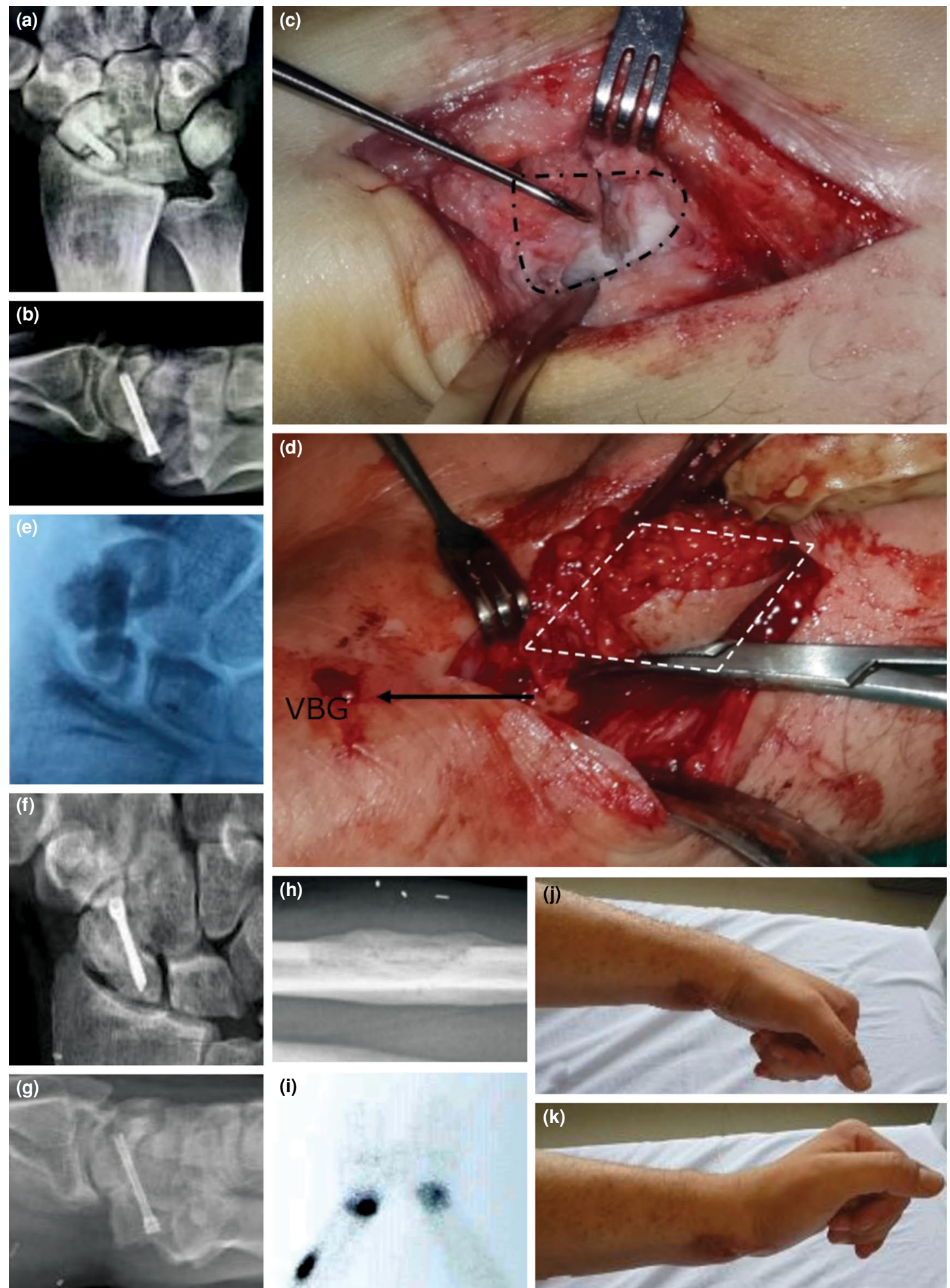

(i)
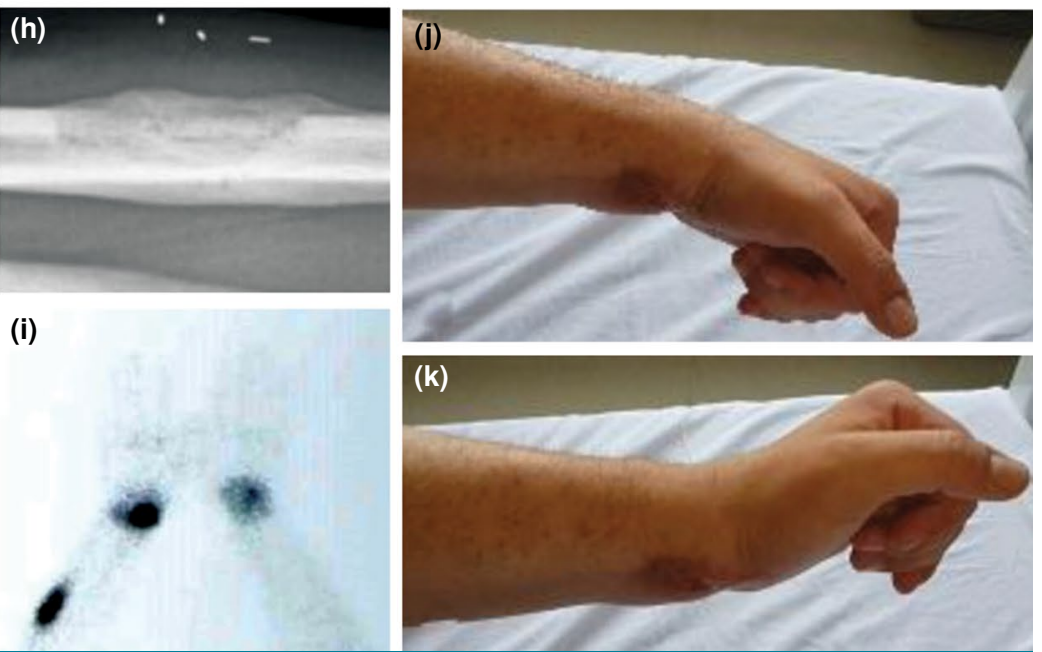

FIGURE 3. Case 1: A 24-year-old male patient with previous scaphoid nonunion surgery with non-vascularized bone graft and headless compression screw reported wrist pain and limited range of motion. (a, b) Preoperative posteroanterior (PA) and lateral radiograph images. (c) Volar approach to scaphoid (dashed lines showing scaphoid). (d) Flap moved to recipient site via subcutaneous tunnel and placed (arrow showing vascularized bone graft, white dashed lines showing monitor flap). (e) Intraoperative X-ray image. (f, g) Postoperative $10^{\text {th }}$ week PA and lateral radiography images. (h) Postoperative $10^{\text {th }}$ week forearm PA radiography image of donor site. (i) Postoperative $10^{\text {th }}$ week scintigraphy image. (j, k) Postoperative $10^{\text {th }}$ week wrist range of motions. 



(f)
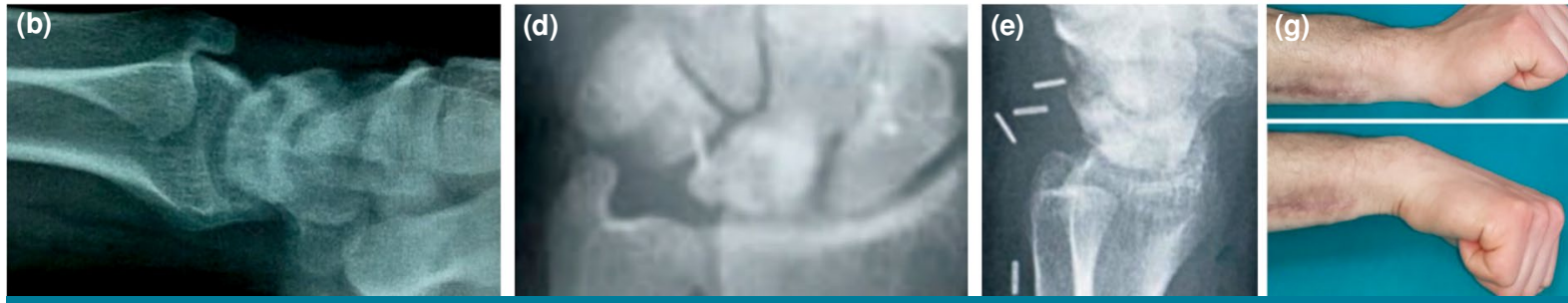

FIGURE 4. Case 2: A 22-year-old male patient was diagnosed with Kienböck's disease in the left wrist due to persistent pain and increasingly limited motion of the wrist after a fall. (a, b) Preoperative PA (posteroanterior) and lateral radiography images. (c) Lunate debridement and revival with burr (arrow) via dorsal incision, flap was transferred through a subcutaneous tunnel (dashed arrow showing vascularized bone graft and its pedicle). (d, e) Postoperative $10^{\text {th }}$ week PA and lateral radiography images. (f) Postoperative $12^{\text {th }}$ week scintigraphy image. (g) Postoperative $12^{\text {th }}$ week wrist range of motions.

total of 51.1 points of decrease was observed in the DASH scores. These patients returned to work after a median duration of 8.5 months (Figure 5).

All the patients' donor site ulnar bones were healed, and no donor site morbidity was observed. There was one patient with traumatic metacarpal defect that had partial skin necrosis of the osteocutaneous flap. The bone component of the flap was alive, and the patient was treated with a $3 \times 2-\mathrm{cm}$ partial-thickness skin graft. No other complications were seen (Table II).

\section{DISCUSSION}

Defects and deformities in bones of the hand and wrist can result from various causes. The primary causes of these bone losses are Kienböck's disease, scaphoid nonunion, Praiser's disease, trauma, and sepsis. ${ }^{[3]}$ Although NVBGs are frequently used to fix these types of bone defects, vascularized grafts are preferred for filling and revitalization of ischemic bone tissue and in revision cases. The VBGs have been reported to be superior to NVBGs in animal

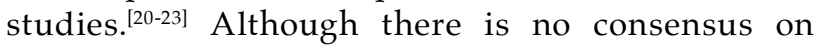
the use of vascularized grafts for large defects, the use of such grafts in hand and wrist bone defects in appropriate cases yields highly successful results. ${ }^{[23,24]}$ Vascularized grafts are usually applied to patients in our clinic with Lichtman Grade 2 and 3A Kienböck's disease, scaphoid osteonecrosis, scaphoid nonunion accompanied by a proximal pole fracture or a previously failed scaphoid surgery.

Bone grafts based on 1,2 intercompartmental supraretinacular artery (ICSRA) and volar carpal artery (VCA) are frequently used in scaphoid nonunion. ${ }^{[2]}$ In Kienböck's disease, 2,3 ICSRA and fourth extracompartmental artery (ECA)-based bone grafts are frequently used. ${ }^{[2]}$ The main disadvantage of vascularized grafts made from radial dorsal bone for scaphoid nonunion (1,2 ICSRA) is that it is difficult to correct the humpback deformity in the scaphoid. In addition, radial styloidectomy is usually required to prevent the vascular pedicle from getting entangled and compressed. Although humpback deformities can be fixed more easily with VCA bone grafts, preoperative surgical procedures on the volar face pose a relative contraindication for this graft. ${ }^{[1]]}$ Although the ulnar artery-based vascularized ulna bone grafts are used for scaphoid nonunion, it is not recommended routinely, as the ulnar artery is sacrificed. ${ }^{[7]}$ In our study, we provided three major advantages concerning the treatment of scaphoid nonunion with ulnar bone graft by using the dorsal ulnar artery. First, we obtained a vascularized graft with a stronger and bigger amount of corticocancellous structure, compared to 

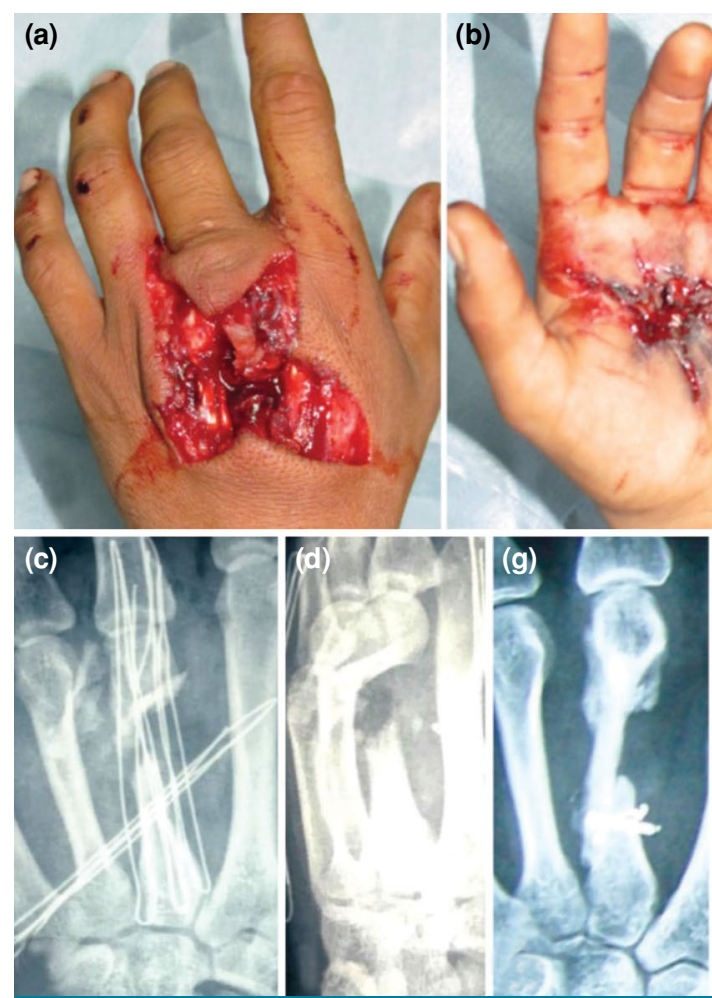
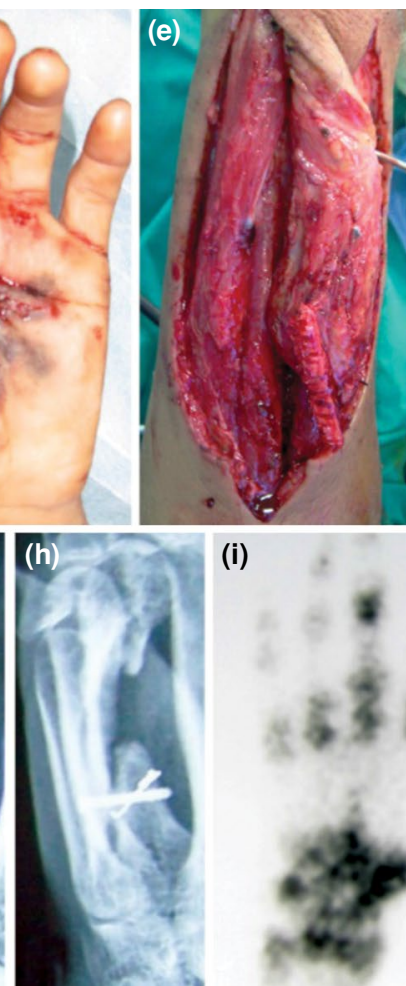

(i)

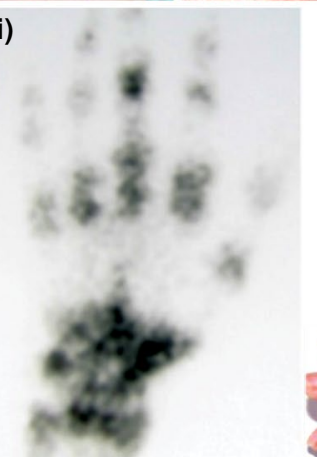

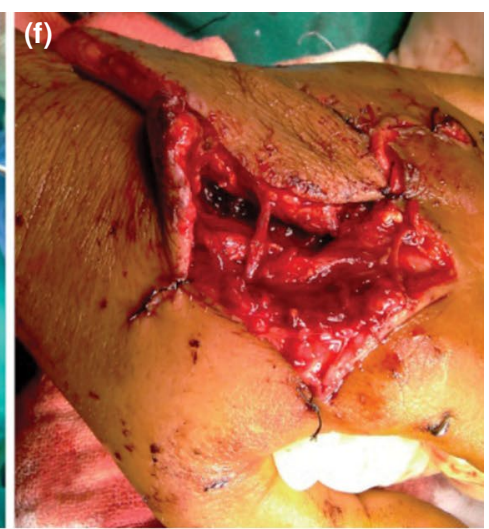


FIGURE 5. Case 3: A 22-year-old male patient who suffered a gunshot injury in his left hand showed a $-40^{\circ}$ restriction of the third finger metacarpophalangeal (MP) joint extension. The patient had a $3 \times 3-\mathrm{cm}$ skin defect at the dorsal side of the hand, a 3.5- $\mathrm{cm}$ long bone defect at the third metacarpal, and a 2-cm extensor tendon defect on the third finger also common digital artery and common digital nerve to the third and fourth digit was disrupted. The graft was fixed cup in cone method distally and with a screw and cerclage wire proximally while the third finger extensor digitorum communis tendon was reconstructed with the palmaris longus tendon taken from the wrist from the same side, common digital artery ligated, nerve was repaired. (a, b) Dorsal and volar images of the hand before the operation. (c, d) Posteroanterior (PA) and lateral radiography images of the hand preoperatively. (e) Elevation of the flap. (f) Flap was adapted to recipient site. $(\mathbf{g}, \mathbf{h})$ The PA and lateral radiography images of the hand postoperative $10^{\text {th }}$ week. (i) Postoperative $12^{\text {th }}$ week scintigraphy image. ( $\mathbf{j}, \mathbf{k})$ Dorsal and side view of the hand at the third month after the operation. A 30 degrees of extension lag and 3-mm metacarpal shortening comparing normal site remained. The patient was unwilling for any further surgical treatment for extension lag.

the vascularized grafts obtained from the radius. Second, the humpback deformity was ameliorated to a greater extent with the surgical incision which was made in the volar face. Finally, VBG's reach to the scaphoid bone became easier thanks to having a longer pedicle.

The 2,3 ICSRA and 4 ECA-based dorsal radial vascular grafts used in Kienböck's disease are suggested as ideal treatment methods. ${ }^{[25,26]}$ Other methods such as vascularized pisiform transfer are reported to be associated with complications of the ulnar nerve. ${ }^{[8]}$ Mathoulin et al. ${ }^{[25]}$ described volar radius-based grafts for patients that had simultaneous radius shortening osteotomy. Nakagawa et al. ${ }^{[27]}$ reported that the choice of graft -dorsal or volar- to be used in Kienböck's disease should be decided on the basis of the location of the collapse in lunate. Although grafting was made dorsally for all our patients with Kienböck's disease, we observed that, having approximately a 6 -cm pedicle length, DUA-based VBGs could reach lunate both dorsally and volarly. In addition, the corticocancellous structure obtained in the vascularized ulnar graft was observed to correct the collapsed parts of the lunate and strengthen the lunate support, particularly in Stage 3a Kienböck's disease patients.

Extremely severe wounds such as those from gunshots result in extensive bony defects which need more complicated treatments. Metacarpal fractures also include damage to the skin and most cases require bone, tendon, and skin reconstruction for which radial artery, ulnar artery, and posterior interosseous artery 
(PIA)-based flaps are mainly used. ${ }^{[28-30]}$ The PIA flaps were mainly preferred in our clinic for the metacarpal region, as it did not sacrifice the main arteries and the bone component could be added. Chopina et al., ${ }^{[16]}$ for the first time, reported the successful addition of bone component from the ulna to a DUA flap in a patient with a metacarpal bone and skin damage. The DUA flaps make it possible to protect the main arteries from destruction and have a flap length of up to $20 \mathrm{~cm}$ and a flap width of up to $6 \mathrm{~cm} \cdot \cdot^{[12-14,31-33]}$ The vascularized corticocancellous graft obtained in this manner could largely cure metacarpal bone defects. Furthermore, the soft tissue component of the flap provides the skin cover. As a result, DUA flaps, whose surgical operation is simpler due to being more superficial, have increasingly become an alternative for PIA flaps in our clinic.

The present study describes the treatment processes of six patients with different diagnoses who were treated with the aforementioned method and who showed improvements in terms of their DASH scores, grip strength, and joint ROM. The primary advantages of this method can be attributed to an easy elevation involved, having a large volume, the presence of a long pedicle and corticocancellous bone. This flap can be a choice, particularly for the revision of scaphoid nonunion that had a failed distal radius VBG surgery and can be an alternative for free flaps as medial femoral condyle. Additionally, since this VBG is diaphyseal, it is mainly cortical and structurally strong, which helps to support the collapsed lunate from whichever side is necessary, dorsal or volar.

The main limitation of the study is that it has a small and heterogenous sample size. Still, there is only one case in the literature in which the DUA-based flap technique was used as an osteofascio-cutaneous flap.

In conclusion, in our study, the treatment processes of six patients were discussed and the indications were expanded for scaphoid and lunate. As a result, the osteo-fascio-cutaneous DUA flap seems to be successful in traumatic metacarpal bone and skin defects. Additionally, DUA-based vascularized ulnar bone may be a source for scaphoid and lunate biological bone reconstruction.

\section{Acknowledgment}

Special thanks to Hüseyin Karagöz for sharing cadaveric dissection figures.

\section{Declaration of conflicting interests}

The authors declared no conflicts of interest with respect to the authorship and/or publication of this article.

\section{Funding}

The authors received no financial support for the research and/or authorship of this article.

\section{REFERENCES}

1. Shin EH, Shin AY. Vascularized bone grafts in orthopaedic surgery. JBJS Rev 2017;5:e1.

2. Klifto CS, Gandi SD, Sapienza A. Bone graft options in upper-extremity surgery. J Hand Surg Am 2018;43:755-61. e2.

3. Derby BM, Murray PM, Shin AY, Bueno RA, Mathoulin CL, Ade $\mathrm{T}$, et al. Vascularized bone grafts for the treatment of carpal bone pathology. Hand (N Y) 2013;8:27-40.

4. Elzinga K, Chung KC. Volar radius vascularized bone flaps for the treatment of scaphoid nonunion. Hand Clin 2019;35:353-63.

5. Karaismailoglu B, Fatih Guven M, Erenler M, Botanlioglu $\mathrm{H}$. The use of pedicled vascularized bone grafts in the treatment of scaphoid nonunion: Clinical results, graft options and indications. EFORT Open Rev 2020;5:1-8.

6. Zaidemberg C, Siebert JW, Angrigiani C. A new vascularized bone graft for scaphoid nonunion. J Hand Surg Am 1991;16:474-8.

7. Guimberteau JC, Panconi B. Recalcitrant non-union of the scaphoid treated with a vascularized bone graft based on the ulnar artery. J Bone Joint Surg [Am] 1990;72:88-97.

8. Saffar P. Vascularized pisiform transfer in place of lunatum for Kienböck's disease. Chir Main 2010;29 Suppl 1:S112-8.

9. Tan Z, Xiang Z, Huang F, Yang Z, Xiao C, Duan X. Long-term results of vascularized os pisiform transfer for advanced Kienböck disease after follow-up for at least 15 years: A case series. Medicine (Baltimore) 2018;97:e13229.

10. Mathoulin C, Brunelli F. Further experience with the index metacarpal vascularized bone graft. J Hand Surg Br 1998;23:311-7.

11. Sommerkamp TG, Hastings H 2nd, Greenberg JA. Palmar radiocarpal artery vascularized bone graft for the unstable humpbacked scaphoid nonunion with an avascular proximal pole. J Hand Surg Am 2020;45:298-309.

12. Becker C, Gilbert A. The cubital flap. Ann Chir Main 1988;7:136-42.

13. Uygur F, Uygur M, Ulkür E, Sever C. Versatility of the reverse dorsoulnar fasciocutaneous flap in coverage of hand defects: Clinical experience with 36 cases. J Hand Surg Am 2009;34:1327-33.

14. Bertelli JA, Pagliei A. The neurocutaneous flap based on the dorsal branches of the ulnar artery and nerve: A new flap for extensive reconstruction of the hand. Plast Reconstr Surg 1998;101:1537-43.

15. Karacalar A, Ozcan M. Preliminary report: The distally pedicled dorsoulnar forearm flap for hand reconstruction. Br J Plast Surg 1999;52:453-7.

16. Choupina M, Malheiro E, Guimarães I, Pinho C, Silva P, Ferreira $\mathrm{P}$, et al. Osteofasciocutaneous flap based on the dorsal ulnar artery. A new option for reconstruction of composite hand defects. Br J Plast Surg 2004;57:465-8.

17. Borges CS, Ruschel PH, Pignataro MB. Scaphoid Reconstruction. Orthop Clin North Am 2020;51:65-76.

18. Aydemir AN, Yücens M, Cansu CE, Demirkan AF. Are plain radiographs reliable in Lichtman classification? Jt Dis Relat Surg 2020;31:34-8. 
19. Takato T, Harii K, Nakatsuka T. The sequential evaluation of bone scintigraphy: An analysis of revascularised bone grafts. Br J Plast Surg 1988;41:262-9.

20. Sunagawa T, Bishop AT, Muramatsu K. Role of conventional and vascularized bone grafts in scaphoid nonunion with avascular necrosis: A canine experimental study. J Hand Surg Am 2000;25:849-59.

21. Tu YK, Bishop AT, Kato T, Adams ML, Wood MB. Experimental carpal reverse-flow pedicle vascularized bone grafts. Part I: The anatomical basis of vascularized pedicle bone grafts based on the canine distal radius and ulna. J Hand Surg Am 2000;25:34-45.

22. Tu YK, Bishop AT, Kato T, Adams ML, Wood MB. Experimental carpal reverse-flow pedicle vascularized bone grafts. Part II: Bone blood flow measurement by radioactive-labeled microspheres in a canine model. J Hand Surg Am 2000;25:46-54.

23. Muramatsu K, Bishop AT. Cell repopulation in vascularized bone grafts. J Orthop Res 2002;20:772-8.

24. Allsopp BJ, Hunter-Smith DJ, Rozen WM. Vascularized versus nonvascularized bone grafts: What is the evidence? Clin Orthop Relat Res 2016;474:1319-27.

25. Mathoulin C, Wahegaonkar AL. Revascularization of the lunate by a volar vascularized bone graft and an osteotomy of the radius in treatment of the Kienböck's disease. Microsurgery 2009;29:373-8.
26. Kakar S, Shin AY. Vascularized bone grafting from the dorsal distal radius for Kienböck's disease: technique, indications and review of the literature. Chir Main 2010;29 Suppl 1:S104-11.

27. Nakagawa M, Omokawa S, Kira T, Kawamura K, Tanaka Y. Vascularized bone grafts from the dorsal wrist for the Treatment of Kienböck Disease. J Wrist Surg 2016;5:98-104.

28. Akdağ O, Yıldıran G, Sütçü M, Karameşe M. Posterior interosseous flap versus reverse adipofascial radial forearm flap for soft tissue reconstruction of dorsal hand defects. Ulus Travma Acil Cerrahi Derg 2018;24:43-8.

29. Glasson DW, Lovie MJ. The ulnar island flap in hand and forearm reconstruction. Br J Plast Surg 1988;41:349-53.

30. Foissac R, Benatar M, Dassonville O, Bozec A, Poissonnet $\mathrm{G}$, Camuzard O. Coverage of tendon exposure after radial forearm free flap by the dorsoulnar artery perforator flap. Otolaryngol Head Neck Surg 2017;156:822-7.

31. Ulkur E, Uygur F, Karagöz H, Celiköz B. Use of free dorsoulnar perforator flap in the treatment of postburn contractures of the fingers. Burns 2006;32:770-5.

32. Tan O, Kılıç M. Supercharged dorsoulnar island flap: A case report and review of the literature. Acta Orthop Traumatol Turc 2011;45:53-7.

33. Vergara-Amador E. The retrograde ulnar dorsal flap: Surgical technique and experience as island flap in coverage of hand defects. Tech Hand Up Extrem Surg 2015;19:90-4. 